\title{
A EDUCAÇÃO AMBIENTAL E AS REPRESENTAÇÕES SOCIAIS DOS PROFESSORES DA REDE PÚBLICA NO ENSINO FUNDAMENTAL
}

\author{
Iraelza de Fátima Coelho Monteiro ${ }^{1}$ \\ Patrícia Diana Edith Belfort de Souza Camargo Ortiz Monteiro ${ }^{2}$
}

Resumo: Este artigo tem o propósito de divulgar parte dos resultados obtidos durante pesquisa realizada com 41 professores de Ensino Fundamental II, da rede pública de um município do Vale do Paraíba paulista, acerca de suas Representações Sociais sobre a prática Educação Ambiental. Este estudo é de natureza qualitativa, descritiva e exploratória e os dados foram coletados por meio de questionários e entrevistas, sistematizados pelo software ALCESTE. A análise de conteúdo deu-se a partir das contribuições de Bardin (2011) e Bauer e Gaskell (2014). Neste artigo, foram consideradas duas classes de significado, a primeira localiza a prática da EA entre as necessidades do cotidiano escolar e a outra contextualiza a discussão a partir da ideia de transformação e responsabilidades socioambientais compartilhadas.

Palavras-chave: Educação Ambiental; Representação Social; Professor da Rede Pública.

${ }^{1}$ Universidade de Taubaté, Taubaté, SP. E-mail: profiraelza@gmail.com

2Universidade de Taubaté, Taubaté, SP. E-mail: patyortizmonteiro@terra.com.br

revista brasileira educação ambiental 


\section{Introdução}

Considerando a estreita relação entre o homem e a natureza, a Educação Ambiental (EA) se manifesta em favor das novas demandas que primam por mudanças comportamentais e estruturais, tendo por base eventos históricos e em desenvolvimento.

Conforme Loureiro et al (2012) as preocupações com a qualidade de vida datam desde a Idade Média.

O início da vida em locais espacialmente definidos como cidades levou à crescente deterioração da qualidade de vida desde a ldade Média. Sob esse ponto de vista, destaca-se, já nessa época, a impressionante precariedade das condições sanitárias e de higiene, [...]. No século XIX, a situação agravouse, com o aumento exponencial da população, cada vez mais concentrada em espaços menores (LOUREIRO et al, 2012, p.41).

Quando analisadas por esse ângulo, a qualidade de vida no âmbito da EA representa grande preocupação com a aprendizagem dos alunos para a dimensão prática. Para o autor (LOUREIRO et al, 2012), a EA deve ser compreendida como uma ferramenta altamente eficaz que se organiza com base na intrínseca relação do homem com o meio ambiente, por meio dos desafios atrelados à formação de valores e ao desenvolvimento humano.

Apesar da representativa importância na qualidade de vida socioambiental no planeta, após a Segunda Guerra Mundial, mais precisamente na década de 1960, iniciaram-se discussões relacionadas às questões da EA. Assim, ampliaram-se os estudos referentes ao tema e, aos estudiosos, coube disseminar à população informações sobre as urgências em cuidar do meio ambiente e a busca pela construção de novos conhecimentos.

Tendo em vista esta trajetória problemática, segundo Sorrentino et al. (2005, p.288), a EA emerge e se manifesta como aliada ao ambiente educativo, com a promessa de ultrapassar os paradigmas que permeiam os interesses ecológicos no campo de atuação social, político econômico.

Nesta concepção, a EA é apresentada como uma estratégia que produz efeitos qualitativos na construção de novos valores e conhecimentos ambientais, no que tange o processo educacional, na condução do cidadão à ética e à responsabilidade social compartilhada.

Nesse cenário, as discussões sobre EA perpassaram os diferentes caminhos da construção do conhecimento, com a indicação dos pesquisadores de que a EA era um conceito que extrapolava as discussões sobre meio ambiente. 
Assim, o nascimento da EA se revela simultaneamente às manifestações advindas dos movimentos socioambientais que se iniciaram após a segunda guerra mundial, conforme salientam Bussolotti e Ortiz (2015), e este nascimento deu-se a partir dos resultados oriundos das catástrofes do século XX, como respostas aos efeitos trazidos pelos eventos da industrialização, comprometendo a qualidade de vida e causando danos ao meio ambiente. Diante desta situação, despontou a necessidade de rever a prática educativa como meio de repensar a atuação humana no planeta.

Para Dias (2001), a questão da EA no cenário brasileiro ainda não atingiu a perspectiva desejável para atender a demanda emergencial contemporânea, podendo ser descrita como fractal e sintomática, haja vista que o processo não se efetiva por não atender as exigências mínimas contidas nos documentos oficiais que regem as normas estruturais sobre a EA no país. Diante disso, o autor (2001) ressalta a relevância para incentivo e fomento às pesquisas e estudos voltados à EA, a fim de alavancar a área e efetivar as propostas indicadas nas diretrizes governamentais.

Nestas circunstâncias, um dos documentos oficiais no contexto histórico educacional brasileiro, os Parâmetros Curriculares Nacionais - PCN (BRASIL, 1998), emerge apresentando propostas assertivas que visam facilitar o desenvolvimento de discussões nas diferentes áreas do conhecimento.

Segundo o PCN (BRASIL, 1998), a EA possibilita ao indivíduo apreender novos valores, com vistas às transformações mentais e comportamentais, na busca pela qualidade de vida, por meio de ações práticas, individuais e coletivas.

A finalidade deste artigo consiste em divulgar parte dos resultados obtidos por meio de estudo realizados com professores de Ensino Fundamental II, da rede pública, de um município do Vale do Paraíba paulista, a partir das suas Representações Sociais - RS acerca da prática da Educação Ambiental EA nas escolas.

\section{Sobre a Educação Ambiental}

De acordo com Morin (2000), o educador possui as condições necessárias para realizar estudos em EA, desenvolvidos e aplicados em uma dinâmica de filosofia de vida, capaz de explorar o comportamento humano para produzir ações que favoreçam as transformações coletivas. Segundo o autor (MORIN, 2000), compreende-se a EA como o próprio conceito de educação, incorporado no processo escolar como um dispositivo capaz de oferecer e garantir melhoria da qualidade de vida.

Dada a relevância da busca pela preservação do planeta, com vistas à sustentabilidade, a EA favorece repensar a formação do cidadão, voltado à prática do consumo consciente e à construção de novos saberes sustentáveis. Neste contexto, as ações do homem, enquanto agente transformador dos 
recursos naturais encontrados no MA, precisam ser reconsideradas, haja vista a condição de responsável pelo manejo da própria vida, assim como dos seres que co-habitam o planeta.

A EA é compreendida como um campo abrangente para estudos voltados à Teoria das Representações Sociais (TRS), haja vista a amplitude e complexidade que permeiam as representações do sujeito, mediante a sua inserção no meio social e sua percepção a respeito do objeto.

Para Chamon et al (2014), a TRS pressupõe que as relações vão se movimentando e se construindo e, portanto, essa teoria não considera a realidade social já construída e concluída, pelo contrário, especifica que a força está nas relações e são os sujeitos que constroem, coletivamente, a realidade social. (CHAMON et al, 2014, p.10).

Dessa forma, importa salientar que a EA se dá, considerando as RS dos professores, com a ocorrência de transformação e mudanças de hábitos, quando se torna reconhecida como prioridade para os órgãos governamentais e estimulada pelas políticas públicas. Ao serem questionados sobre o próprio comportamento, os docentes refletem que a EA é compreendida a partir da prática cotidiana, no envolvimento que favorece estudos e atividades realizadas no ambiente escolar que promovam a transformação de atitude, postura e comportamento das pessoas no meio em que estão inseridas.

\section{Metodologia}

A pesquisa organiza-se a partir de um estudo qualitativo, de natureza aplicada, exploratória e descritiva. Fundamenta-se na Teoria das Representações Sociais (TRS), de Serge Moscovici, precursor da teoria.

Sempre e em todo lugar, quando nós encontramos pessoas ou coisas e nos familiarizamos com elas, tais representações estão presentes. A informação que recebemos é à qual tentamos dar um significado, está sob seu controle e não possui outro sentido para nós além do que elas dão a ele. (MOSCOVICI, 2011, p.40)

Haja vista que para Moscovici (2011, p.40-41), as Representações Sociais (RS) caracterizam-se, todas, a partir do desenvolvimento coletivo, consequência do processo histórico da interação entre os grupos humanos que se manifestam na convivência cotidiana das pessoas e dos laços sociais estabelecidos entre os grupos, o presente estudo pode ser analisado à luz da TRS, considerando a perspectiva dos professores para compreensão.

Os interlocutores da pesquisa foram reunidos em um grupo composto por 41 professores, da rede pública de um município da Vale do Paraíba paulista, que ministram aulas do $6 \stackrel{\circ}{\text { ao }} 9 \stackrel{\circ}{\circ}$ ano do Ensino Fundamental nas 
diferentes áreas do conhecimento que compõe o currículo: Língua Portuguesa, Matemática, História, Geografia, Ciências, Artes, Inglês, Ensino Religioso e Educação Física.

Entre os instrumentos metodológicos utilizados para coleta de dados, optou-se pela aplicação de questionário objetivo, utilizado para caracterização sociodemográfica dos sujeitos, além de entrevistas realizadas oralmente, a partir de roteiro pré-estruturado. Posteriormente, todo material foi transcrito integralmente, tanto os questionários quanto as falas obtidas em entrevistas.

Os dados coletados a partir das transcrições foram preparados $\mathrm{e}$ analisados pelo programa ALCESTE (Analyse Lexicale par Contexte d'un Ensemble de Segmentes de Texte), um software criado na França, na década de 1970. Enquanto técnica, o ALCESTE investiga, sistematiza, analisa os dados textuais, através de transcrições orais e, enquanto metodologia, 0 ALCESTE realiza uma classificação hierárquica a partir de três etapas que se complementam: a) leitura do texto; b) definição das unidades de contexto elementares; e c) descrição da classificação efetuada.

Dessa forma, todas as falas obtidas nos questionários e nas entrevistas puderam ser sistematicamente submetidas ao programa ALCESTE, para serem analisadas, operacionalizadas e agrupadas por classes, conforme a proximidade dos discursos, gerando classes de significados. As classes a serem analisadas nesse artigo foram denominadas "Cotidiano" e "Mudanças", contextualizando com as evidências identificadas a partir dos discursos.

Para desenvolver a análise de conteúdo, utilizou-se Bardin (2011), que orientou a pesquisa de modo a validar os dados coletados e apresentar maior rigor nos resultados (BARDIN, 2011, p. 131).

Além disso, buscou-se contribuição nos estudos metodológicos de Bauer e Gaskell (2014, p.203), que identificam as bases a partir das quais uma pesquisa pode ser considerada de natureza social. Tais autores salientam que a análise de conteúdo é uma construção, oriunda a partir do contexto social, em que o corpus de texto alia-se à própria realidade e deve ser julgados conforme seu resultado, observação metodológica fundamental para toda a trajetória da pesquisa aqui relatada.

\section{Resultados}

Entre os 41 professores participantes da pesquisa, havia 16 homens e 15 mulheres, distribuídos por todas as disciplinas que compõem o currículo para o segundo ciclo do Ensino Fundamental. Em ordem decrescente, foram: sete professores na área de Geografia; seis na área de Ciências; cinco professores de Matemática, Educação Física e Língua Portuguesa; na área de Ensino Religioso foram quatro professores; três provenientes das disciplinas de Artes e Inglês; dois professores de História; e um professor especialista.

A participação durante a pesquisa era voluntária e ainda que haja um destaque para a participação de professores das disciplinas de Geografia e 
Ciências, houve relativa participação de outras áreas do conhecimento. Essa identificação com a temática da EA e com o próprio objeto da pesquisa já indica que as RS dos professores a respeito da prática da EA no Ensino Fundamental dialogam com os pressupostos dos documentos norteadores do Governo Federal, especialmente com os PCN.

Cada professor pode contribuir decisivamente ao conseguir explicitar os vínculos de sua área com as questões ambientais, por meio de uma forma própria de compreensão dessa temática, de exemplos abordados sobre a ótica de seu universo de conhecimento e pelo apoio teórico - instrumental de suas técnicas pedagógicas (BRASIL, 1997, p.195).

Sendo assim, a partir do número de professores participantes e a distribuição deles por diversas áreas de conhecimento coincide com a questão abordada pelo $\mathrm{PCN}$, de que a responsabilidade pela qualidade na educação perpassa o desenvolvimento da EA. Além disso, tanto o PCN quanto os professores participantes deste estudo, demonstram que a noção de responsabilidade compartilhada passa a ser importante elemento constitutivo das RS, norteando as práticas relativas à EA.

A partir dos dados coletados ao longo da pesquisa, foram geradas algumas classes de significado e, para fins deste artigo, duas classes se destacaram como importantes na construção dos resultados e foram selecionadas.

Os principais agrupamentos gerados a partir das classes estão representados por meio de mapas mentais que buscam facilitar a visualização dos resultados obtidos. Por meio da análise dos mapas mentais, é possível verificar como os professores dispensam apreço às questões relacionadas à $E A$, de uma forma tão familiar que é citada inúmeras vezes pelo conjunto de professores, como uma das principais ferramentas capaz de reunir qualidades indispensáveis na harmonia do cotidiano escolar.

Optou-se por identificar como "Cotidiano" a classe que apresenta agrupamento de discursos que representam o aprendizado no cotidiano, no que concerne tanto o aluno quanto o professor. Como elemento essencial à compreensão das RS dos professores a respeito da prática da EA no Ensino Fundamental II, a EA aparece constituída de oportunidades que probabiliza como uma aliada na interação e participação dos atores escolares (Figura 1).

Este agrupamento representa o que os docentes da pesquisa pensam sobre a EA no que tange aos novos conhecimentos e à necessária mudança de atitude e comportamento dos alunos mediante as questões ambientais mais amplas. Os discursos demonstram que as mudanças comportamentais só ocorrem frente à construção de novos conhecimentos e à aquisição de novos hábitos, a partir do trabalho e da reflexão por meio das situações corriqueiras. 


\section{Classe "Cotidiano"}

\section{Discussão da prática da EA entre as necessidades das práticas cotidianas}

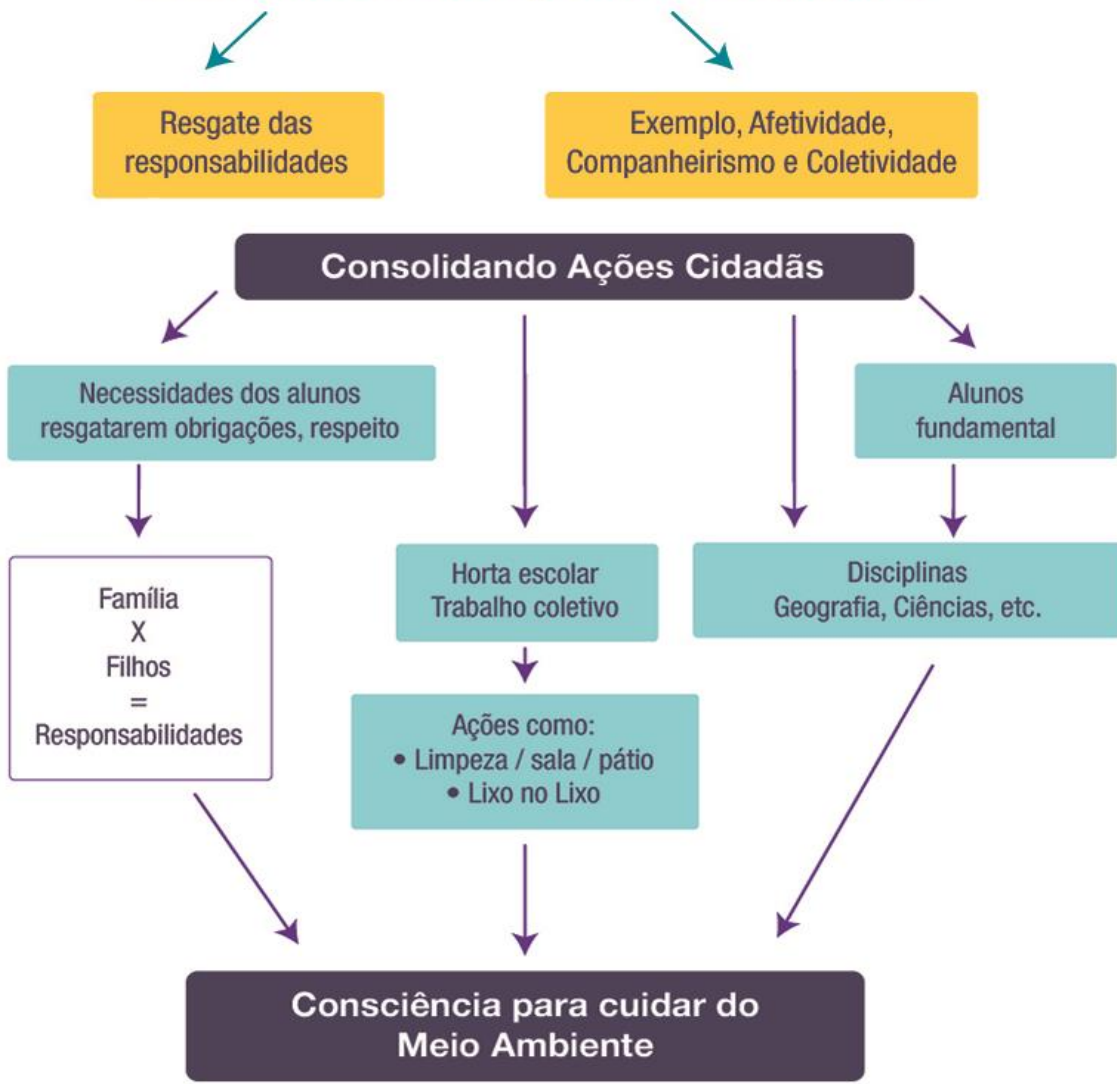

Figura 1: Mapa esquemático da Classe "Cotidiano" Fonte: elaborado pelas autoras.

Este agrupamento - "Cotidiano" - indica que as RS dos professores julgam que o desenvolvimento de ações críticas que encaminham a formação cidadã se dê em decorrência das diferentes disciplinas que fazem parte do currículo. Pressupõem os docentes, a partir dos discursos apresentados neste agrupamento, que as ações inter-relacionadas a partir das atividades de EA em consonância com os conteúdos abordados no currículo se consolidariam em mudanças de comportamento idealizados pela EA.

Para Kondrat e Maciel (2013, p.825), a espécie humana, no desenvolvimento pleno da sua sabedoria, revolucionou o mundo, contudo, o 
modo de vida só se torna possível graças à sua integração com o MA. Sendo assim, nessa classe, "Cotidiano", o grupo de professores propõe atividades concretas que podem ser integradas ao espaço caracterizado como MA, e ser realizadas dentro e fora da sala de aula. Sugere-se, nesta abordagem, que os conteúdos disciplinares podem ser abordados por meio de tarefas cotidianas, como a organização da própria sala de aula e a limpeza do pátio da escola, ou o cultivo de uma horta escolar orgânica, inclusiva, sob a responsabilidade dos próprios alunos.

Os docentes sugerem, ainda, a possibilidade de interação social, envolvendo a escola e a comunidade escolar, no compartilhamento de compromissos que transcendam a construção entre o saber ecológico e o saber social, conforme revela o discurso de um dos professores deste estudo.

A educação ambiental ela, se num primeiro momento, se entende simplesmente como plantar árvore ou coisa dessa natureza tá mal entendido isso, né? Porque a educação, a educação do ambiente passa pela limpeza, passa pela cidadania, passa pelo relacionamento e em todos os sentidos e, logicamente também pela parte ambiental, física, de plantação de árvore, seja como cuidar de uma horta etc. ${ }^{3}$ (RESPONDENTE DA ESCOLA IDENTIFICADA COMO ARAUCÁRIA ${ }^{4}$ ).

Dessa forma, a classe "Cotidiano" representa o fortalecimento de laços afetivos entre escola e família por meio da EA, considerada como fundamento para construção da cidadania em sua plenitude. É a oportunidade de a escola estabelecer vínculos de cidadania, a partir de relações cordiais que conduzam para práticas políticas e sociais.

Neste contexto, Higuchi e Azevedo (2004) salientam que:

As crianças, adolescentes e jovens passam a maior parte do tempo na escola. Ela, portanto, torna-se o local de referência dos valores da e na sociedade. [...]. Por isso a escola deve ser um espaço onde o corpo discente e docente estejam envolvidos e comprometidos na construção de um ambiente saudável, harmonioso e equilibrado (HIGUCHI; AZEVEDO, 2004, p.66).

${ }^{3}$ As falas dos professores serão apresentadas em itálico e foram transcritas de modo fidedigno, o que possibilita ocorrências características da oralidade, como erros gramaticais e repetições.

4 Para garantir o anonimato dos docentes, as escolas das quais esses são provenientes foram identificadas a partir de nomes de árvores exemplares da flora brasileira. 
As autoras compreendem que a reflexão sobre a relação do homem com o ambiente é uma discussão pertinente frente à contemporaneidade social e a escola, na sua complexidade, oferece condições especiais que propiciam essa forma de aprendizagem.

Segundo as RS dos docentes da pesquisa, é preciso uma nova consciência de respeito e companheirismo para ressignificar a relação entre homem e o MA.

A classe "Mudanças", selecionada para este estudo, apresenta as RS dos docentes organizadas de forma mais abrangente. Neste quadro, as RS divulgam que a temática voltada à EA pode ir além da sala de aula e explorar o entorno escolar, com vistas no envolvimento das políticas públicas neste contexto.

\section{Classe "Mudança"}

Discussão de EA entre transformação, mudanças de hábitos e responsabilidades socioambientais

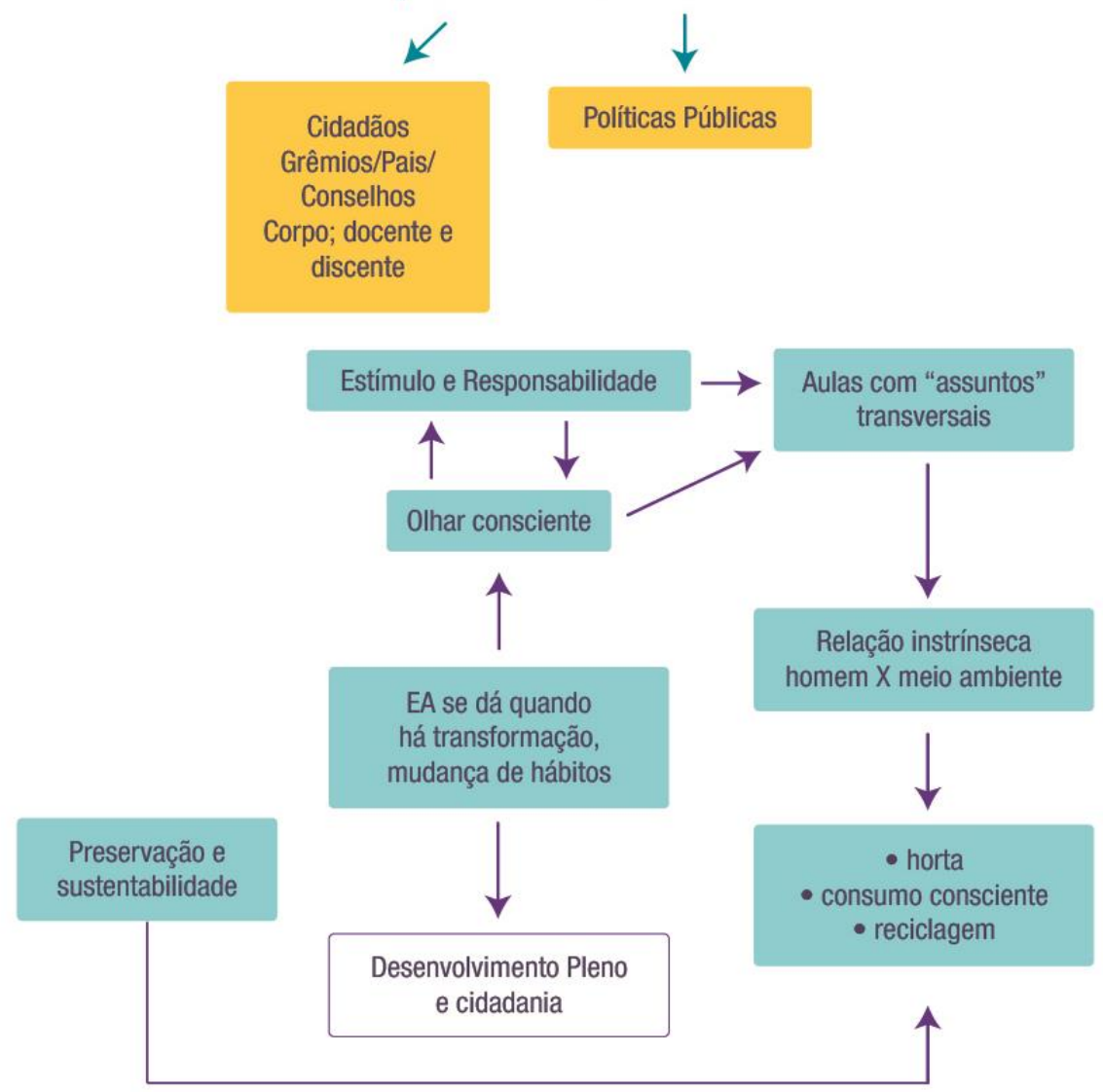

Figura 2: Mapa esquemático da Classe "Mudanças"

Fonte: elaborado pela autora.

Revbea, São Paulo, V. 12, № 1: 165-176, 2017.

revista brasileira educação ambiental 
$\mathrm{Na}$ visão desses docentes os temas mais relevantes sobre EA envolvem o bem estar da população. Retratam a importância da temática e discutem que a EA se dá quando ocorre mudança de hábitos; tanto das escolas, com os colegiados escolares, alunos e famílias, como pela participação dos cidadãos responsáveis pelas políticas públicas.

Quando questionado se a EA pode se reverter em benefícios que visem melhorias para a comunidade, um dos professores participantes da pesquisa, atuante na Escola Araucária, responde:

[...] é nesse sentido que eu acho que a Educação Ambiental influencia os alunos e influencia os professores. Quando você vê que a escola não é pichada, quando os alunos não deixam lixo no chão. Quando você não tem tantos conflitos na escola, quando existe um bom relacionamento entre os próprios colegas. Quando, apesar da escola ser uma escola simples, ela tem um, uma jardinagem, ela tem flores na entrada. Então, eu enxergo que é nesse sentido que a gente pode afirmar e confirmar que a Educação Ambiental está dando bons resultados (RESPONDENTE DA ESCOLA IDENTIFICADA COMO ARAUCÁRIA).

Neste discurso percebe-se a repercussão dada às coisas simples. A EA pode ser traduzida em valores que podem repercutir e fazer a diferença, impactando a reflexão entre alunos e equipe escolar. Assim, o software ALCESTE classifica pontos marcantes nos discursos que orientam para a necessidade do desenvolvimento de novas metodologias.

Partindo do pressuposto que os professores representam, por meio dos seus discursos, suas crenças e valores que os afligem no dia a dia, cabe ressaltar que as suas RS valorizam a importância de se enveredar para caminhos que conduzam a reconstruções nas formas de ensinar e aprender, motivando reformas do sistema educacional, por meio da inserção em conselhos municipais e órgãos participativos.

Cabe acrescentar que a EA se dá, segundo as RS dos professores, quando há transformação e mudanças de hábitos, mas também, quando se é reconhecida como prioridade para os órgãos públicos e estimulada pelas políticas públicas.

O último ponto a se destacar na Classe "Mudanças" é a questão da indisciplina, indicada pelos docentes da pesquisa como o maior desafio para o trabalho docente no geral. Contudo neste aspecto, as próprias RS dos docentes apresentam a EA como importante aliada para minimizar essa dificuldade no cotidiano da escola.

No cruzamento dos dados obtidos, foi possível perceber, a partir da análise reflexiva das entrevistas, amparadas ao arcabouço teórico, 
semelhanças nas manifestações manejadas à prática da EA desenvolvida nas escolas, para a formação integral do cidadão.

\section{Considerações}

Partindo do pressuposto que as RS são fenômenos que orientam o comportamento coletivo, sugere-se que as RS são reflexos do conhecimento reificado ligado à vivência dos professores no cotidiano escolar e os resultados deste estudo podem apresentar o indivíduo limitado nas possibilidades relativas aos aspectos cognitivos e afetivos.

Considerando a análise dos discursos, deparou-se com pontos demarcados pelos professores e que, assim, orientam suas RS a respeito da prática da EA nas escolas de Ensino Fundamental II. As reflexões perpassam a preocupação com a preservação e a conservação ambiental, tomam como ponto de partida as reflexões que despertam o interesse que envolve os diferentes atores em busca de melhor qualidade de vida e sustentabilidade. Considerando esse contexto, as RS dos docentes reforçam a importância da EA associada à noção de interdisciplinaridade, enfatizando que as disciplinas não devem, segundo suas representações, atuar isoladamente. Por fim, os resultados do estudo revelam que o grupo de professores compreende a importância da EA como uma ferramenta facilitadora no processo reflexivo entre professores e alunos, mas evidenciam que para abarcar o trabalho direcionado à temática, efetivamente, precisam de formação constante.

Mesmo quando os docentes representam que têm dificuldades na execução dos trabalhos inerentes ao contexto escolar e apontam as responsabilidades da formação para os órgãos públicos, reconhecem que é na escola que as coisas acontecem.

Apesar dos professores da rede pública do ensino fundamental trazerem em suas RS a EA como prática cotidiana na escola e a reconhecerem como objeto transformador responsável por mudanças na qualidade de vida dos envolvidos, a EA não é trabalhada na escola de forma interdisciplinar, como citada nos PCN. Entretanto as escolas desenvolvem atividade de EA, ora orientadas pela Secretaria Municipal de Educação, ora por iniciativas da gestão escolar e do grupo de professores. 


\section{Referências}

AZEVEDO, D.M., COSTA, R.K.S. e MIRANDA, F.A.N., Uso do ALCESTE na análise de dados qualitativos: Uma contribuição na pesquisa em enfermagem. Revista de Enfermagem UFPE Online, Recife, 7, Jul,2013.

BARDIN, L., Análise Conteúdo. Tradução Luis Antero Reto, Augusto, Pinheiro, São Paulo: Edições 70. 2011.

BAUER, M.W. GASKEL, G. Pesquisa Qualitativa com texto, imagem e som. Um manual prático. Tradução de GUARESCHI, P.A., Ed Vozes, 12 edição. 2014.

BRASIL. Parâmetros Curriculares Nacionais, PCNs, 1997, 1998.

BUSSOLOTTI, J.; ORTIZ. P. Educação Ambiental para Sustentabilidade. Livro texto para Programa de Educação à distância da Universidade de Taubaté, Taubaté: UNITAU, 2015.

CHAMON, E.M.Q.O., et al. Apresentação. In: CHAMON, E.M.Q.O.; GUARESCHI, P.A.; CAMPOS, P.H.F. (orgs). Textos e debates em representação sócia I. Porto Alegre, ABRAPSO, 2014.

DIAS, G.F. A situação da Educação Ambiental no Brasil é fractal. In: Panorama da Educação Ambiental no Ensino Fundamental. / Secretaria de Educação Fundamental / Coordenação-Geral de Educação Ambiental. COEA. Coord. Lucila Pinsard Vianna - Brasília: MEC; SEF, 2001.

HIGUCHI, M.I.G.; AZEVEDO G.C. Educação como processo na construção da cidadania ambiental. Revista Brasileira de Educação Ambiental. Brasília: Rbea - Rede Brasileira de Educação Ambiental, 2004.

KONDRAT, H.; MACIEL, M. Delourdes. Educação ambiental para a escola básica: contribuições para 0 desenvolvimento da cidadania e da sustentabilidade. Rev. Bras. Educ., Dez 2013, vol.18, no.55, p.825-846. Disponível em: <http://www.scielo.br/pdf/rbedu/v18n55/02.pdf> Acesso em 18/11/2016.

LOUREIRO,C.F.B. et al. Sociedade e meio ambiente: a educação ambiental em debate. -7.ed.- São Paulo: Cortez, 2012

MINAYO, M.C.S.; ASSIS, S.G.; SOUZA E.R, (Orgs). Avaliação por Triangulação de Métodos: Abordagem de Programas Sociais. Rio de Janeiro: Editora Fiocruz, 2005.

MORIN, E. Os Sete Saberes Necessarios à Educação do Futuro. BRASÍLIA (DF): CORTEZ, UNESCO, 2000.

MOSCOVICI, S., Representações sociais: investigações em psicologia social. 8ed.-Petrópolis, RJ: Vozes, 2011.

SORRENTINO et al. Educação Ambiental como política pública. Educação e Pesquisa, São Paulo, v.35, no 2, p. 285-299, mai/ ago, 2005. Disponível em: <http://www.scielo.br/pdf/ep/v31n2/a10v31n2.pdf> Acesso em 22/11/2015. 